\title{
The Utilisation of Images in the Teaching of Lessons
}

\author{
Archontia Foutsitzi \\ Laboratory Teaching Staff, Department of Primary Level Education \\ Democritus University of Thrace
}

\begin{abstract}
The use of educational tools in teaching is a crucial issue, bearing in mind that their contribution has been pointed out on various occasions by many researchers. Images are one of the tools which contribute to the learning process. This is the reason why most teachers use visual materials when teaching lessons. The aim of this study is to highlight the contribution and the usefulness of images in teaching through the teachers' actions.
\end{abstract}

Keywords: image, illustration, image and education.

\section{Introduction}

Apart from the terms, the content, the direction and the technical organisation in teaching (Matsangouras, 2006), an important topic dealt with by the science of Didactics is that of educational tools (Salvaras \& Salvara, 2011), which teachers use to provide either physical or intellectual support for the learning process to be carried out. By means of this process concrete knowledge is acquired, skills and abilities are developed (Konstantinou, 2015) and values are formed (Hatzidimou, 2011). Teachers, in recognition of the pedagogical value which these tools provide, have included them when teaching almost all of their lessons (Taratori-Tsalkatidou, 2005; Hatzidimou, 2015). Among these, images occupy a prime position.

Images are a medium for expressing all "two-dimensional visual representations of persons, objects or phenomena" (Kanakis, 1999). According to a more general definition, an 'image' is "the material representation of a real or imaginary object" (Zangotas, 2016), which was created with the aim of showing a person, thing or phenomenon, which is not present. However, it was soon realised that what it depicts is, ultimately, more valuable than a mere representation, because every image, apart from being representational, also signifies many other things in itself. This fact has given it greater potency and longevity and its roles has ceast to be temporary and transitory. For this reason it has been considered particularly important and useful to have the presence of images. Thus images have gradually invaded and become established in many areas, also including that of education.

Images have pride of place in education today. School textbooks are full of images (Palikidis, 2009), because illustrations play a role which is multifaceted and has multiple meanings. Their contribution to the teaching is not one-dimensional, but depends each time on the function they are required to perform. Thus images sometimes supplement the texts which they accompany, sometimes provide additional information besides that presented in the narrative of the texts and sometimes decorate and embellish the pages of a book.

The development of technology, in conjunction with the introduction of IT in education (Kron \& Sophos, 2007), has provided many teachers with the possibility of using images in the teaching of their lessons not only in a printed form by also in a digital one (Newby, Stepich, Lehmann \& Russel, 2009; Kontakos \& Stamatis, 2017). In this way, a traditional means of teaching has been developed into a modern educational tool, which, due to its diversity and the abundance of the possibilities which it offers, has become established as an important teaching aid.

\section{Starting point, goal and methodology of the research}

The importance of illustrative material in implementing the educational process formed the starting point for the carrying out of research. The goal of the research was to assess the contribution of images in the teaching of lessons, based on the teachers' activities. In order for this goal to be achieved and for the research to be implemented, a questionnaire was used as a research tool for collecting data (Keeves, 1990; Daoutopoulos, 2002; Zafeiropoulos, 2005; Cohen, Manion \& Morisson, 
2008). The processing of the statistics for the research data was carried out with the aid of the SPSS (Statistical Package for the Social Sciences) programme (Kelpanidis, 1999; Roussos \& Tsaousis, 2011).

\section{Analysis of the research data}

Two hundred and eighty eight teachers participated in the research. Of these 63 were men (a percentage of 20.5\%) and 225 were women (a percentage of 79.5\%) (Table 1).

\section{Table 1.}

Distribution of teachers according to their gender

\begin{tabular}{lll}
\hline \hline Gender & Frequency & Percentage (\%) \\
\hline \hline Men & 63 & 20.5 \\
Women & 225 & 79.5 \\
& & \\
\hline \hline Total & 288 & $100 \%$ \\
\hline \hline
\end{tabular}

The majority of the respondents (180 individuals, a percentage of $62.5 \%$ ) were teachers who taught general education subjects, whilst 108 of them (a percentage of $37.5 \%$ ) taught specialist subjects (Table 2).

\section{Table 2.}

Distribution of teachers according to their specialism

\begin{tabular}{lcc}
\hline \hline Specialism & Frequency & Percentage (\%) \\
\hline \hline Teachers & 180 & 62.5 \\
Specialist teachers & 108 & 37.5
\end{tabular}

\begin{tabular}{lcc}
\hline \hline Total & 288 & $100 \%$ \\
\hline \hline
\end{tabular}

The teachers who took part in the survey were asked to answer the following questions:

how much do you carry out an observation of the images each time that you use them when teaching a lesson? how much do you ask for an explanation of their content when you refer to these images? how much do you comment on them? how much do you try to analyse their individual elements each time you include them when teaching a lesson? how much do you examine their content more closely when you show them in the lesson? how much do you think that the use of images during a lesson contributes to the understanding of the concepts contained within it?

how much do you think that the use of an image helps to increase the pupils' interest and attention? how much do you think that images contribute to the creation of clear representations of the content of a lesson? how much do you think that showing images in class boosts the pupils' self-motivation? how much do you think that the use of images gives the teaching an individual character? how much do you think that the presence of images contributes to an increase in the pupils' range of visual representations? 
All the questions included in this section of the questionnaire were "close-ended" and the possible answers to these were: "not at all", "a bit", "quite a lot" and "a lot".

From the answers collected it can be seen that 143 teachers (a percentage of 50.9\%) stated that they encourage their pupils "very much" to observe a picture before expressing any opinion about its contents. One hundred and twenty-two of these (a percentage of $43.4 \%$ ) encourage them "quite a lot", whilst only 15 teachers (a percentage of $5.3 \%$ ) ask the pupils in class "a bit" to carry out this activity (Table 3 ).

Table 3.

Observation of images

\begin{tabular}{lll}
\hline \hline Answers & Frequency & Percentage (\%) \\
\hline \hline Not at all & 1 & .4 \\
A bit & 15 & 5.3 \\
Quite a lot & 122 & 43.4 \\
A lot & 143 & 50.9 \\
No answer (missing) & 7 & - \\
\hline \hline Total & 288 & $100 \%$ \\
\hline \hline
\end{tabular}

One half of the teachers in the survey (141 individuals, a percentage of $50.4 \%$ ) stated that the images contained in one of their teaching modules encouraged them "quite a lot" to explain the individual components to be found in these. One hundred and eleven teachers (a percentage of $39.6 \%$ ) do this "a lot", whilst 27 of their colleagues (a percentage of $9.6 \%$ ) chose the answer "a bit" (Table 4)

\section{Table 4.}

\section{Explanation of the contents of a picture}

\begin{tabular}{lll}
\hline \hline Answers & Frequency & Percentage (\%) \\
\hline \hline Not at all & 1 & .4 \\
A bit & 27 & 9.6 \\
Quite a lot & 141 & 50.4 \\
A lot & 111 & 39.6 \\
No answer (missing) & 8 & - \\
\hline \hline Total & 288 & $100 \%$ \\
\hline \hline
\end{tabular}

One hundred and twenty-six teachers in this survey (percentage of 45.5\%) get involved "quite a lot" in making an extensive commentary on the contents of the images. There was a similar number of teachers (124 individuals, a percentage of $44.8 \%$ ), who carry out this activity "a lot". Twenty-five of their colleagues (a percentage of $9 \%$ ) however, encourage their pupils "a lot" to comment on the images which they encounter during the teaching of their lessons, whilst there were 2 teachers (a percentage of .7\%) who do not do this "at all" (Table 5).

\section{Table 5.}

Commentary on the images

\begin{tabular}{lll}
\hline \hline Answers & Frequency & Percentage (\%) \\
\hline \hline Not at all & 2 & .7 \\
A bit & 25 & 9 \\
Quite a lot & 126 & 45.5 \\
A lot & 124 & 44.8 \\
No answer (missing) & 11 & - \\
\hline \hline Total & 288 & $100 \%$ \\
\hline \hline
\end{tabular}


One hundred and thirty-two teachers in the survey (a percentage of 47\%) analyse "quite a lot" the details of an image which they come across in a teaching module. One hundred and two of them (a percentage of $36.3 \%$ ) analyse the content of an illustration "a lot", whilst 43 of their colleagues (a percentage of 15.3\%) attempt this "a bit". However, there were also 4 teachers (a percentage of 1.4\%) who do not analyse the content of the images within a subject module "at all" (Table 6).

Table 6.

Analysis of the individual details of images

\begin{tabular}{lll}
\hline \hline Answers & Frequency & Percentage (\%) \\
\hline \hline Not at all & 4 & 1.4 \\
A bit & 43 & 15.3 \\
Quite a lot & 132 & 47 \\
A lot & 102 & 36.3 \\
No answer (missing) & 7 & - \\
\hline \hline Total & 288 & $100 \%$ \\
\hline \hline
\end{tabular}

To the question "whether and to what extend do teachers go deeply into the content of an image included in the teaching of their lessons", 117 of them (a percentage of $41.9 \%$ ) stated that they do this "quite a lot". Ninety-two of their colleagues (a percentage of $33 \%$ ) carry out this activity "a lot", whilst 65 teachers (a percentage of $23.3 \%$ ) do it "a bit". Five of those asked in the survey stated that they do "not at all" go deeply into the content of the images which they come across in a teaching module which they are dealing with (Table 7).

Table 7.

Going deeply into the content of the images

\begin{tabular}{lll}
\hline \hline Answers & Frequency & Percentage (\%) \\
\hline \hline Not at all & 5 & 1.8 \\
A bit & 65 & 23.3 \\
Quite a lot & 117 & 41.9 \\
A lot & 92 & 33 \\
No answer (missing) & 9 & - \\
\hline \hline Total & 288 & $100 \%$ \\
\hline \hline
\end{tabular}

One hundred and thirty-six of the teachers who took part in the survey (a percentage of $47.7 \%$ ) testified that images help their pupils "a lot" in understanding the concepts of the lesson. One hundred and thirty-two of them (a percentage of 46.3\%) selected the statement "quite a lot", whilst 16 of their colleagues (a percentage of $5.6 \%$ ) think that images contribute in this field "a bit" (Table 8).

\section{Table 8.}

Contribution of images to the understanding of concepts

\begin{tabular}{lll}
\hline \hline Answers & Frequency & Percentage (\%) \\
\hline \hline Not at all & 1 & .4 \\
A bit & 16 & 5.6 \\
Quite a lot & 132 & 46.3 \\
A lot & 136 & 47.7 \\
No answer (missing) & 3 & - \\
& & \\
\hline \hline Total & 288 & $100 \%$ \\
\hline \hline
\end{tabular}


Two hundred and nine teachers from the survey sample (a percentage of $73.6 \%$ ) acknowledged that images contributed "a lot" to increasing the pupils' the interest and attention. Sixty-seven of their colleagues (a percentage of 23.6\%) consider this contribution as being "quite a lot", whilst 8 teachers (a percentage of $2.8 \%$ ) stated that images contributed "a bit" to an increase in the pupils' interest and attention during a lesson (Table 9).

Table 9.

Contribution of images to an increase in the pupils' interest and attention

\begin{tabular}{lll}
\hline \hline Answers & Frequency & Percentage (\%) \\
\hline \hline A bit & 8 & 2,8 \\
Quite a lot & 67 & 23,6 \\
A lot & 209 & 73,6 \\
No answer (missing) & 4 & - \\
& & $100 \%$ \\
\hline \hline Total & 288 & \\
\hline \hline
\end{tabular}

The images used by the teachers in the survey sample in the teaching of their lessons helped them "a lot" to create clear representations. This view was shared by 131 teachers (a percentage of 46.5\%), whilst another 126 of their colleagues (a percentage of $44.7 \%$ ) agreed that this occurred "quite a lot". A small percentage of the teachers (7.8\%) thought that images contribute "a bit" in this direction, whilst yet another 3 of their colleagues (a percentage of 1.1\%)claimed that images do not help "at all" in this field (Table 10).

Table 10.

Contribution of images in creating clear representations

\begin{tabular}{lll}
\hline \hline Answers & Frequency & Percentage (\%) \\
\hline \hline Not at all & 3 & 1 \\
A bit & 22 & 7.8 \\
Quite a lot & 126 & 44.7 \\
A lot & 131 & 46.5 \\
No answer (missing) & 6 & - \\
\hline \hline Total & 288 & $100 \%$ \\
\hline \hline
\end{tabular}

Images contribute "quite a lot" to pupils' self-motivation according to statements by 146 teachers (a percentage of 51.8\%) of the survey sample. For 68 of their colleagues (a percentage of $24.1 \%$ ) this contribution is "a lot", whereas, on the contrary, for another 60 teachers (a percentage of 21.3\%) the amount by which images contribute to the boosting of pupils' selfmotivation is "small". Finally, there were 8 teachers (a percentage of .3\%) who did not share this view "at all" (Table 11).

Table 11.

Contribution by images in boosting pupils' self-motivation

\begin{tabular}{lll}
\hline \hline Answers & Frequency & Percentage (\%) \\
\hline \hline Not at all & 8 & .3 \\
A bit & 60 & 21.3 \\
Quite a lot & 146 & 51.8 \\
A lot & 68 & 24.1 \\
No answer (missing) & 6 & - \\
\hline \hline Total & 288 & $100 \%$ \\
\hline \hline
\end{tabular}


To the question "how much do images contribute to the individual character of the teaching of the lesson?", 129 teachers taking part in the survey (a percentage of $45.6 \%$ ) thought that this was achieved "quite a lot". Sixty-three of their colleagues (a percentage of 22.3\%) described this contribution as being "a lot". There were, however, also quite a few teachers (82) who held the opposite view, since $29 \%$ percent stated that this contribution was at a "small" rate. Lastly, 9 teachers (a percentage of 3.2\%) thought that images did not contribute "at all" to giving the teaching of a lesson an individual character (Table 12).

Table 12.

Contribution of images to giving teaching an individual character

\begin{tabular}{lll}
\hline \hline Answers & Frequency & Percentage (\%) \\
\hline \hline Not at all & 9 & 3.2 \\
A bit & 82 & 29 \\
Quite a lot & 129 & 45.6 \\
A lot & 63 & 22.3 \\
No answer (missing) & 5 & - \\
\hline \hline Total & 288 & $100 \%$ \\
\hline \hline
\end{tabular}

It appears that 158 teachers (a percentage of $56.6 \%$ ) of the survey sample identified the contribution of images in increasing the pupils' range of visual representations as being "a lot". One hundred of their colleagues (a percentage of $35.9 \%$ ) described this contribution as being "quite a lot", whilst 19 of these (a percentage of $6.8 \%$ ) thought that this was occurring "a bit". Lastly, 2 teachers (a percentage of .7\%) claimed that, based on their experience, this kind of contribution did not occur "at all" (Table 13).

\section{Table 13}

Contribution of images in increasing pupils' range of visual representations

\begin{tabular}{lll}
\hline \hline Answers & Frequency & Percentage (\%) \\
\hline \hline Not at all & 2 & .7 \\
A bit & 19 & 6.8 \\
Quite a lot & 100 & 35.9 \\
A lot & 158 & 56.6 \\
No answer (missing) & 9 & - \\
\hline \hline Total & 288 & $100 \%$ \\
\hline \hline
\end{tabular}

\section{Conclusions}

According to the findings of the survey, the teachers taking part rated the contribution of images to the activity of teaching as being positive. For this reason they have been taking a series of actions aimed at achieving a more substantial and deeper involvement with these images. In particular, they try, to a great extent, to involve pupils in procedures which consist of observing in detail all the information contained and included in an image (Dimitriadou, 2007). They then ask them fairly regularly to explain the content of the image and to comment on its individual details. Going one step further, they encourage them to analyse their features in detail and to go into these more deeply (Vryzas, 1990). These actions are necessary for each teacher so that the images are not used as decorative and attractive items in the classroom, but as dynamic tools which promote and support learning

By implementing the above activities, images have been shown to be valuable didactic tools which contribute to the understanding of the lesson being taught (Simatos, 2003). Their incorporation into the activity of teaching is a necessity, because many concepts in the lesson are thereby explained and clarified. However, the teachers' specific aim is to increase the pupils' attention (Hatzidimou \& Hatzidimou, 2014) and their interest. By using bright colours and details they aim to arouse their pupils' interest and "nail down" their attention to the lesson. 
In addition to the above, an illustration helps a lot in increasing the pupils' range of visual representations. Using images reinforces the children's imagination (Kitsaras, 1993) and the mechanism for creating mental representations. Images help quite a lot in developing the pupils' self-motivation. This means that an image is a "good" medium, which gives the pupil the chance to express himself and to communicate with the other pupils in his class. Through these communication procedures (Stamatis, 2012) his self-confidence is increased and his self-motivation is reinforced. Thus the teacher, taking into account how the dynamics of a class are made up and his pupils' specific characteristics and requirements, can try to create an individually-tailored teaching curriculum (Hatzidimou, 2015). According to what the participants in the survey have stated, images help quite a lot in this direction.

\section{Biblography}

[1] Cohen, L., Manion, L. \& Morrison, K. (2008). The Methodology of Educational Research. Athens: Metaichmio. [in Greek]

[2] Daoutopoulos, G. (2002). Social Research Methodology. Thessaloniki: Zygos. [in Greek]

[3] Dimitriadou, K. (2007). Visual literacy and language teaching: a critical reading of Greek language textbooks for the First Year at Junior School. Modern Education, 148, 72-80. [in Greek]

[4] Hatzidimou, D. (2011). Introduction to Pedagogy. Contribution to the dissemination of pedagogical thinking. Thessaloniki: Kyriakidis Brothers Publishing House S.A. [in Greek]

[5] Hatzidimou, D. (2015). Microteaching in teacher training. A theoretical and empirical approach. Thessaloniki: Kyriakidis Brothers Publishing House S.A. [in Greek]

[6] Hatzidimou, D. (2015). Introduction to the Thematics of Teaching. Contribution to the theory and practice of teaching. Thessaloniki: Kyriakidis Brothers Publishing House S.A. [in Greek]

[7] Hatzidimou, D. \& Hatzidimou, K. (2014). Planning of Teaching in theory and in practice. Educational - didactic techniques, lesson plans and teaching scenarios for primary school, secondary school and high school. Athens: Diadrasi. [in Greek]

[8] Kanakis, I. (1999). Teaching and learning with modern teaching materials. Athens: Grigori. [in Greek]

[9] Keeves, J. (Ed.) (1990). Educational Research, Methodology and Measurement: An International Handbook. Oxford: Pergamon.

[10] Kelpanidis, M. (1999). Methodology of Pedagogical Research with Statistical Data. Thessaloniki: Kodikas. [in Greek]

[11] Kitsaras, G. (1993). Illustrated books at the infant and pre-school age. Athens: Papazisi. [in Greek]

[12] Konstantinou, Ch. (2015). The good school, the capable teacher and appropriate education. Athens: Gutenberg. [in Greek]

[13] Kontakos, A. \& Stamatis, P. (Ed.) (2017). Communication Theories and Models in Education. Athens: Diadrasi. [in Greek]

[14] Kron, F. \& Sophos, A. (2007). Teaching Media. Athens: Gutenberg. [in Greek]

[15] Matsangouras, I. (2006). Theory of Teaching. Personal Theories as a Framework for Reflective Critical Analysis.Athens: Gutenberg. [in Greek]

[16] Newby, T., Stepich, D., Lehman, J. \& Russel, J. (2009). Educational technology for teaching and learning. Thessaloniki: EPIKENTRO S.A. [in Greek]

[17] Palikidis, A. (2009). The role of images in History Textbooks in Secondary Education. (1950-2002). Thessaloniki: Kyriakidis Brothers Publishing House S.A. [in Greek]

[18] Roussos, P. \& Tsaousis, G. (2011). Statistics in the behavioural sciences with the use of SPSS. Athens: Topos. [in Greek]

[19] Salvaras, G. \& Salvara, M. (2011). Teaching models and strategies. Athens: Diadrasi. [in Greek]

[20] Simatos, A. (2003). Technology and education. Choice and use of visual aids. Athens: Patakis. [in Greek]

[21] Stamatis, P. (2012). Communication in the educational and administrative process. Basic concepts and strategies. Athens: Diadrasi. [in Greek]

[22] Taratori-Tsalkatidou, E. (2005). Primary School Lesson Planning. Thessaloniki: Kyriakidis Brothers Publishing House S.A. [in Greek]

[23] Vryzas, K. (1990). Communication and education media. Contemporary Education, 51, 77-89. [in Greek]

[24] Zafeiropoulos, K. (2005). How to write a scientific paper; Athens: Kritiki. [in Greek]

[25] Zangotas, B. (2016). The multisensory dynamic of images in the teaching process. Thessaloniki: Kyriakidi. [in Greek] 